International Journal of Engineering \& Technology, $7(4.38)(2018) 469-473$
International Journal of Engineering \& Technology
WPC

\title{
Communicative Failures and Their Causes as a Result of Unsuccessful Communication
}

\author{
Rezeda Dilshatovna Shakirova ${ }^{1^{*}}$, Adelina Renatovna Safina ${ }^{1}$, Raisa Rustyamovna Akhunzianova ${ }^{1}$

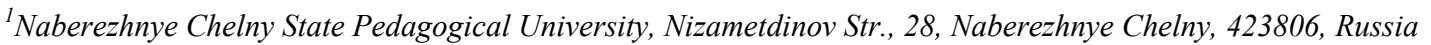 \\ *Corresponding author E-mail: shakirova.r.d@bk.ru
}

\begin{abstract}
The article treats the phenomenon of a communicative failure as a result of unsuccessful communication and analyses the factors leading to this occurrence. The research is based on the communicative-pragmatic method, which considers a variety of pragmatic factors affecting the realization of the communicative situation, and the descriptive method which is oriented on studying the language as a system of units and rules of their use. The illustrative basis consists of the situations expressing the meanings of epistemic possibility and epistemic necessity. The research enables us to single out six groups of reasons which can serve as factors leading to a communicative failure: disregard for the norms of social and speech etiquette, inadequate perception of the interlocutor and phenomena of the extralinguistic reality, communicative failures as a result of the influence of the personality of the participants of communication and background information that the interlocutors possess, failure in the realization of the communicative intention of the speaker, intentional or unintentional striving for a communicative failure, inability to build a speech utterance. The indicated factors lead to the conclusion that they are often determined by the difference of an intra-cultural character, and the use of epistemic markers on the whole does not affect the success of communication.
\end{abstract}

Keywords: communication, communicative situation, communicative failure, epistemic possibility, epistemic necessity, modal words.

\section{Introduction}

The notion of communication is relatively wide and concerns various fields of study. Basing his research on the existing scientific approaches to the treatment of this phenomenon and the spheres of realization of communicative activity, A.Yu. Bykov groups them in the following mode: the first meaning regards the field of study of social sciences - it is communication of information in society "in the process of social activities of a person"; the second meaning is connected with the study of biology and presupposes biological communication (interaction); the third meaning concerns technical sciences and implies passageways, means of connection and various technical systems; finally, the fourth meaning refers to "exchange of information in inanimate nature" and is studied by exact sciences [1]. Using the term of "communication" in this article we denote "a specific form of personal interaction" [2] in the process of joint social activities, which is accompanied by transmission and processing of information (thoughts, ideas, images, notions, knowledge, emotions, feelings etc.) about the phenomena of extra-linguistic reality, which apart from passing information to the interlocutor facilitate forming their outlook, changing their perception of objective reality, correcting their behavior etc. Following the vision of S. M. Gass, E. M. Varonis [3], E. C. Olsina [4] by successful communication we mean a type of communicative interaction in which the message encoded by the speaker and the message decoded by the listener are "symmetrical" - this facilitates understanding and agreement between the participants of communication. Hence, as unsuccessful communication there can be marked the case of communication in which the message coded by the speaker remains unapprehended or misunderstood by the listener, which leads to a communicative failure.

Communication or, regarded more narrowly, speech communication, is realized in the frames of a communicative (speech) situation, as O.S. Akhmanova [5] states. Communicative situation is a complex and many-sided phenomenon which is a popular object of study in modern linguistics. It is a context of speech, in other words "those conditions (circumstances, aim) under which the utterance takes place" [5]. The same viewpoint is held by J. A. Fishman who defines communicative situation as interaction of two or more interlocutors who are connected by a certain mode, communicate on a certain topic and under certain circumstances [6]. T. V. Matveyeva [7] views communicative situation

"a process of speech interaction of interlocutors which is limited in space and time, is complete, socially meaningful and taking a certain form $<\ldots>$ a generalized model of conditions and circumstances determining the speech behavior of a person". Following N. I. Formanovskaya [8] by communicative situation we denote "a complex sum of exterior conditions of communication and inner states of the interlocutors, presented in the speech product - an utterance, discourse". The basic components of a communicative situation are participants of communication, while A. Mustajoki [9] draws our attention to the fact that the situation has only indirect reference to the content that the speaker intends to express as this content is always limited and interpreted by the speaker under the influence of the speaker's communicative needs. The present article has as its aim revealing the notion of a communicative failure as a result of unsuccessful communication, as well as an attempt of classifying the reasons of communicative failures marked by the use of epistemic operators. 


\section{Methods}

The theoretical basis for the actual research comprises the works of Russian and foreign linguists in the field of communicative linguistics, such as S.Ye. Bugrova, Ye.A. Popova, S.M. Gass, E. M. Varonis, E. C. Olsina and other scholars. The research is carried out in the frames of communicative-pragmatic and anthropocentric approaches. This is due to two reasons: the analysis of the communicative situation, which consists of a number of pragmatic factors affecting the choice of epistemic markers by the speakers, and orientation to the personalities of the participants of communication, holding the principal position of the creators of speech products, because "the factor of a human in language becomes crucial" [10]. Speaking of particularly linguistic methods, it can be stated that the research is hold in the frames of the descriptive method focusing on the facts and phenomena of one language, English in this case. The techniques of the descriptive method include observation, generalization, interpretation and classification which are used while carrying out the present research.

\section{Results}

Communicative situation is characterized by the participants of communication having a common communicative intention oriented towards achievement of mutual understanding and reaching a consensus with regard to the topic of conversation. For communication to be successful it is crucial that both interlocutors should be interested in communication, accept and understand each other's inner world, should not intrude into each other's personal space, interpret each other's communicative intentions correctly. Other important factors comprise identical presuppositions, speech preparedness, the interlocutors' abilities of varying the lexical part of their speech, psychological comfort of the speech situation, benevolence, mutual respect and kindness of the interlocutors towards each other, neutral emotional state of the participants of the communication, regard for the cooperative principle of Grice, the politeness principle of G. Leech, the code of speech behavior of T. V. Shmelyova, cooperativity and other conditions. Disregard for any of the enumerated conditions can lead to a communicative failure.

The conducted research enables us to single out nineteen causes of communicative failures which are characterized by the use of modal markers of epistemic possibility (further on - EP) or epistemic necessity (further on - EN), the majority of which are not dependent on the cultural or linguistic characteristics of the participants of communication. It seems possible to group the causes in the following way: I) disregard for the norms of social and speech etiquette (breaking the norms of speech behavior, breaking etiquette stereotypes); II) inadequate perception of the interlocutor and phenomena of the extra-linguistic reality (different mental worlds and inadequate recipient-design; perception of the interlocutor as of a person they not really are; inadequate evaluation of the actions or personal qualities of the listener by the speaker; alien communicative surrounding); III) communicative failures as a result of the influence of the personality of the participants of communication and background information that the interlocutors possess (peculiarities of character; stereotypes of speech behavior and thinking; wrong presuppositions and implications; difference in evaluation of phenomena of reality; violation of parity of communication); IV) failure in the realization of the communicative intention of the speaker (the wrong discerning of the communicative intention of the interlocutor; intentional ignoring of the communicative intention of the interlocutor; the wrong choice of a communicative strategy and the tactics of its realization); V) intentional or unintentional striving for a communicative failure (lack of readiness for cooperation; breaking the postulates of communication; "communicative sabotage"); VI) inability to build a speech utterance (inexact transmission of somebody else's speech; inability to express thoughts in a logical way).

\section{Discussion}

\subsection{Introductory Remarks}

In the process of communication, alongside with the striving for the achievement of the common aim, each participant of communication can pursue their private subjective goals which should, nevertheless, be in accordance with the common aim of the speech interaction. Involved in a communicative process, a speaker cannot be directed only by their own desires and needs, since negation of the presence of addressee factor (in other words, the significance of the listener as an active participant of communication) is a reason sufficient for a communicative failure. However, it should be underlined that one of the basic causes of communicative failures is lack of understanding on the part of the listener. This lack of understanding can be a result of linguistic or extra-linguistic factors. C. Bazzanella and R. Damiano [11] distinguish five language levels where misunderstanding can occur: phonetic, lexical, syntactic, semantic and pragmatic, lexical and pragmatic levels being relevant for the actual research.

\subsection{Treatment of the Communicative Failure Phenomenon}

According to D. Verdonik [12], the most productive period in the foreign study of communicative failures was that of 70-90s of the XXth century. A number of linguists reveal the nature of communicative failures in the scope of clinical linguistics (R. Angeleri, B. G. Bara, A. Bono, F. M. Bosco, M. Bucciarelli, D. Keen,

K. Sacco, J. Volden and others). The study of the phenomenon continues into the modern period of the development of the linguistic science. S. Ye. Bugrova [13] treats the communicative failure phenomenon in the frames of a communicative-pragmatic paradigm. S. V. Kiseleva [14] analyses communicative failures in the texts of political discourse. Ye. A. Popova [15] aims to find out the reasons of communicative failures in English dialogic speech. Ye. V. Shelestyuk [16] proposes pragmalinguistic analysis of a communicative failure in a communicative act of a dialogue in Internet communication. Since communicative failures are the result of mental activities of the participants of communication, of interest is an approach of G. Airenti, B. G. Bara, M. Colombetti, F. M. Bosco, M. Bucciarelli [17-20] whose research is conducted in the scope of cognitive pragmatics to enable examination of the psychic processes involved in understanding and creating of communicative acts. Concurrently F. M. Bosco, M. Bucciarelli and B. G. Bara [20] consider the notion of "repair" a communicative failure which consists in a new attempt of creating the desirable communicative effect, as well as the ways of correcting communicative failures.

\subsection{The Notion of a Communicative Failure}

There can be observed certain differences in terminology on definition of the communicative situation characterized by the absence of successful and efficacious communicative interaction, which

in different sources is treated as a communicative failure (S. Ye. Bugrova, B. Yu. Gorodetsky, N. I. Formanovskaya, S. V. Kiseleva, N. K. Kneva, T. V. Larina, V. S. Lukyanova, A. Mustajoki, Ye. V. Paducheva, S. Ye. Polyakova, Ye. A. Popova, A. A. Potyomkin, A. Yu. Serebryakova, Ye. V. Shelestyuk, O. N. Yermakova and Ye. A. Zemskaya; W. Faulkner, B. Keysar, E. C. Olsina, A. Tzanne, D. Zaefferer), performative failures (J. Austin), communicative (speech) breakdown (O. A. Machina, Ye.V. Smorgonskaya), communicative error (N. I. Drakina, 
M. Yu. Kopylovskaya, Ye.M. Yepihina), communicative impediment (T.A. Ladyzhenskaya), conversation failure (M. Ringle), communicative (verbal, linguistic) conflict (L. V. Chaika, S. G. Ilyenko), communicative discomfort (N. M. Bolohontseva), communicative misunderstanding (K. F. Sedov). Communicative failures are a result of spontaneity of dialogic speech in the production of which the participants of communication demonstrate inability to express their thoughts clearly and distinctly, to discern the communicative intentions of each other unwillingness to listen to and to hear each other, and, consequently, inability to interpret the speech message of the interlocutor correctly and react to it in an adequate way. As N.K. Kneva [21] views it, a communicative failure has a semanticpragmatic nature and is "a kind of pragmatic incomprehension" which is a consequence of the wrong transmission of the propositional content by the speaker, erroneous interpretation of the utterance by the listener, or both of these factors. It should be noted, that in the process of communication interlocutors do not always present true and authentic information, as a result of which communicative situations with one or all the participants operating with unreliable or partly reliable data, which are received from the sources that may not be trustworthy, are observed on a daily basis and lead to communicative failures.

Following the conception of Ye. A. Zemskaya and O.N. Yermakova [22], we define a communicative failure as "complete or partial incomprehension of the utterance" by the speaker, as a result of which the communicative intention of the speaker remains unrealized, as well as "occurring in the process of communication undesirable emotional effect, unforeseen by the speaker: resentment, irritation, amazement". A communicative failure may result in a response of the listener, unforeseen by the speaker (achievement of the unplanned perlocutionary effect), or absence of reaction. In both cases the communicative intention of the speaker remains unrealized.

B. Yu. Gorodetsky, I. M. Kobozeva and I. G. Saburova [23] distinguish implicit and explicit, wide and narrow, global and partial, strategic and tactical communicative failures; communicative failures caused by the participant of communication and those caused by the conditions of the communicative act. F. M. Bosco, M. Bucciarelli and B. G. Bara [6] single out failure of the expression act and failure of the actor's meaning, which are further on divided into non-comprehension and misunderstanding of the communicative act and failure of the communicative effect, which in its turn is constituted by rejection of the move (a weak denial of the actor's proposal by the partner), and refusal to play the game (a strong denial).

\subsection{Causes of Communicative Failures}

As the principal causes of communicative failures Ye. A. Zemskaya and O. N. Yermakova [22] name: 1) language organization 2) difference between interlocutors (individually psychological, social, gender, age characteristics etc.); 3) pragmatic factors.

The analysis of the existing approaches to the treatment of the phenomenon of communicative failures enables us to single out and group the following reasons which lead to a failure in communication. The research was focused on the utterances expressing epistemic meanings:

I) disregard for the norms of social and speech etiquette:

1) violation of the rules of speech behavior. The following example deals with the speaker's attempt of justifying his actions, an attempt that fails due to the inappropriate use of the modal word (further on - MW) of EP probably accompanied by familiarity towards the listener:

"You must see that, Teresa - »

«My name is Teresa Alves,» she cut in. $<\ldots .>$

«Miss Alves, this is probably the most important discovery of my entire life. $<\ldots>$ This Ben, is unique.»

«Ben Lovatt. His name is Ben Lovatt.»

This really did silence him (D. Lessing «Ben, in the World»).
2) breaking etiquette stereotypes, disregard for social norms of relationship. For example, the following conversation of unfriendly interlocutors instead of greetings starts with insults and threats on the part of the listener, which causes the speaker's laughter and unwillingness to continue communication:

«Waiting for someone?» I say at the window.

«Don't you get an inch closer,» she says. <..> «What are you, some kind of hippie now? God, your poor mama must be so embarrassed of you.»

«Hilly, why are you here?»

«To tell you I've contacted my lawyer <...>. You're going to jail, you know that? <..> I am here to inform your mother of what you've done.»

«You're going to tell my mother on me?» I laugh (K. Stockett «The Help»).

II) inadequate perception of the interlocutor and phenomena of the extra-linguistic reality:

1) different mental models/worlds and "inadequate recipientdesign" as a result of "common ground fallacy" [24] (the speaker disregards the addressee factor). In the following example he speaker is sure that that the listener shares his vision of the ideal society in which every family brings up one or two children. However, as it turns out during the conversation, the listener adheres to the idea of an exemplary society in which large families are possible:

«Think about it $<\ldots>$. Sometimes you two scare me.» $<\ldots>$

«Perhaps we ought to have been born into another country. Do you realize that having six children, in another part of the world, it would be normal, nothing shocking about it - they aren't made to feel criminals» (D. Lessing «The Fifth Child»).

2) erroneous perception of the interlocutor as of a person they are actually not (according to their social status or role, psychological attitudes). As an illustration, see the example in which a farther perceives his son as his copy, as a person that has the same aspirations (this is marked by a MW EN of course). Unwillingness to see the son as a personality with his own wishes and needs leads to a communicative failure:

«Of course you can win,» my father said quickly. «We Carters always win.»

$<\ldots>$ «But what if I don't want to?»

$<\ldots>$ «I think,» he said slowly, «that it would be a good idea» (N. Sparks «A Walk to Remember»).

3) inappropriate or inadequate (in the given communicative situation) evaluation by the speaker of actions or personal qualities of the listener because of unfriendly attitude towards the latter. In the example cited below comparison of the girl's actions with the actions of a mad person causes her anger and willingness to insist on her desire, which is marked by MW EN of course: «It's crazy,» said Dorothy. < ..>

«Of course everyone has to come,» Harriet said, weeping - and ran out of the room (D. Lessing «The Fifth Child»).

4) communicative act taking place in an inappropriate ambient / at an inappropriate time / with strangers present ("alien communicative surrounding" according to S. I. Vinogradov [25]. For example, a visit paid at the moment when the interlocutor was having a rest at home does not dispose her to a productive conversation; unwillingness of the woman to listen to the boy is marked by MW EN really:

She said, «Christopher, I really don't think I want to see you right now.»

I said, «I didn't kill Wellington.»

And she replied, «What are you doing here?» (M. Haddon «The Curious Incident of the Dog in the Night-Time»).

III) communicative failures as a result of the influence of the personality of the participants of communication and background information that the interlocutors possess:

1) features of character. In the following example the obstinacy of children as well as of their parents, which is marked by MW EN certainly, really, the certainty of the parents that the children must be made to change their mind alongside with the confidence of the 
children who think that they know the best way of acting in the situation, leads to an argument:

«You aren't really going to have four more children?» enquired Sarah $<\ldots$...

«Yes, we are,» said David.

«Yes, we certainly are,» said Harriet. «This is what everyone wants, really, but we've been brainwashed out of it.» $<$... $>$

«We are the centre of this family. <..> Not you, Mother.»

«God forbid,» said Molly <... .

«It's never been your style.»

«It's certainly never been mine,» said James, «and I'm not going to apologize for it» (D. Lessing «The Fifth Child»).

2) stereotypes of speech behavior and thinking can be illustrated by the example given below in which the male perception of receiving presents is contrasted to the female position in regard to the question, as a result of which the listener's hint remains overlooked:

«Could you open it for me? My hands are kind of full right now.» $<\ldots>$

«You don't have to open it now <...>, it's really not that big of a deal.»

«Don't be silly <...> I would only open it in front of you» (N. Sparks «A Walk to Remember»).

3) wrong presuppositions and implications are reflected in the following illustration of a communicative failure, in which the speaker tries in vain to convince the interlocutor that one cannot trust people blindly basing his arguments on the example of a woman who is well familiar to the listener:

«The mail-woman. If she had a key, she could leave things inside our door.»

«But you can't give a key to a stranger.»

«Fortunately Alicia isn't a stranger.»< <..>

«Sometimes people who seem good end up being not as good as you might have hoped, you know? What if she had stolen your things?»

«She wouldn't.»

«But what if?»

«But she wouldn't» (J. S. Foer «Extremely Loud \& Incredibly Close»).

4) difference in evaluation of phenomena and events of objective reality. In the following example, the speaker does not succeed in his attempt (marked by MW EN obviously) of convincing the listener of false information, as the speaker's evaluation of the conditions under which the child lives is drastically different from the evaluation of those by the listener:

«And you put Ben into a cage like an animal, without clothes.»

$\ll<\ldots>$ it was obviously a misunderstanding.»

Teresa said, «I think the misunderstanding was that you did not expect us to find him like that» (D. Lessing «Ben, in the World»). 5) violation of parity of communication characterized by violation of the "rule of solidarity, cooperation of interlocutors" [25], which can be illustrated by the following example with the MW EN of course. The listener who considers herself wiser, more experienced in political matters and having a better status in society, uses her authority to make the interlocutor change her viewpoint. However, the attempt leads to a communicative failure as the speaker holds to a fundamentally different opinion on the matter:

«I want them back, Hilly. You took them and they don't belong to you.»

«Of course I took them. You have no business carrying around something like that. What if somebody saw those things?»

"Who are you to say what I can and cannot carry ar-» (K. Stockett «The Help»).

IV) failure in the realization of the communicative intention of the speaker:

1) the wrong discerning of the communicative intention of the interlocutor. In the example given below a woman tries to persuade Christopher to stop his investigation, introducing into her speech the EP markers perhaps, maybe and EN obviously, but her communicative intention is not realized because of Christopher's wrong interpretation of the reasons why his father might not approve of his actions:

«Perhaps it would be best not to talk about these things, Christopher.»

And I asked, «Why not?»

And she said, $\ll<\ldots>$ Because maybe your father is right and you shouldn't go around asking questions about this.»

And I asked, «Why?»

And she said, «Because obviously he is going to find it quite upsetting.»

And I said, «Why is he going to find it upsetting?»< ..>

«Because... because I think you know why your father doesn't like Mr. Shears very much.»

Then I asked, «Did Mr. Shears kill Mother?» < ..>

$<\ldots>$ «No. No. Of course he didn't kill your mother» (M. Haddon

«The Curious Incident of the Dog in the Night-Time»).

2) intentional ignoring of the communicative intention of the interlocutor, which can be illustrated by the example in which the father ignores his son's attempts of building a logical chain in his investigation while the son ignores the father's prohibition of carrying out the investigation and mentioning the main suspect:

I said, «I think Mr. Shears probably killed Wellington.»

Father didn't say anything.

I said, «He is my Prime Suspect. Because I think someone might have killed Wellington to make Mrs. Shears sad. And a murder is usually committed by someone known $-»$

Father $<\ldots>$ shouted, «I will not have that man's name mentioned in my house. $<\ldots>$ That man is evil.»

And I said, «Does that mean he might have killed Wellington?»

Father put his head in his hands and said, «Jesus wept» (M. Haddon «The Curious Incident of the Dog in the Night-Time»).

3 ) the wrong choice of a communicative strategy and the tactics of its realization. In the following example the listener resorts to a communicative strategy of sincerity, the tactics of an appeal to the "voice of reason" (with epistemic markers can't and of course), trying to help the girl understand the absurdity of her wish. None the less, the attempt fails due to the constant emotional and psychic tension the girl experiences, which prevents her from viewing the situation in an adequate way:

«It will all be easier when Christmas starts,» wept Harriet.

"You can't be serious,» said David, furious. «Of course they can't come this Christmas.»

«But it is so easy when people are here, everyone helps me» (D. Lessing «The Fifth Child»).

V) intentional or unintentional striving for a communicative failure:

1) unreadiness of the interlocutors for cooperation is reflected in the example quoted below: unobtrusive desire to help (expressed by MW EP maybe) results in interlocutor's irritation and finally leads to an argument:

«You're not in a very good mood, are you?» she finally asked. $<\ldots>$

«You don't miss a thing, do you?» I said sarcastically $<\ldots .>$.

«Maybe I can help,» she offered. <...>

«I doubt it,» I snapped.

«Maybe if you told me what was wrong - »

I didn't let her finish (N. Sparks «A Walk to Remember»).

2) violation of the postulates of communication. Taking into consideration Grice's cooperative principle, which is based on four categories of quantity, quality, relation and manner, in the following conversation we can observe a communicative failure as a result of disregard for the category of quality, since the speaker intentionally presents false information which leads to a response inadequate to the real situation:

«Landon, $<\ldots>$ You look like you've been exercising,» she said.

«Not really» <... $>$.

"You've sweat clean through your shirt.»

«Oh, that? < .. > I just sweat a lot sometimes.» 
«Maybe you should have it checked by a doctor» (N. Sparks «A Walk to Remember»).

3) "communicative sabotage". In the following conversation unobtrusive requests of the speaker to share the details of the listener's family life, marked by MW EN really and EP maybe, lead to a strongly negative reaction and refusal to continue the conversation:

«Minny, do you and Leroy ever talk about civil rights? <..>» «Nope» was all Minny said. Minny do not like people up in her business.

«Really? He doesn't share the way he feels about the marches and the segregation? Maybe at work, his bo-»

«Move off a Leroy.»<...>

«Minny, maybe-»)<..>

«I ain't doing this no more» (K. Stockett «The Help»).

VI) inability to build a speech utterance:

1) inaccurate transmission of somebody else's speech. As it can be seen from the example below, the woman's prudence while transferring to the interlocutor the words of her mistress results in Minny's ignoring the intention of the speaker to warn her and instead of becoming more prudent in her actions and words towards the mistress, demonstrates open irritation, aggression and a desire to take revenge on the mistress for the slander:

«I think I heard Miss Hilly say something about that, bout her mama getting skinny.» I say this careful as I can. «Say maybe she getting mal-nutritious. < .. > I think she got her eye on you, Minny. Just... be extra careful around her.»

«Miss Hilly ought to be extra careful around me. What she say, I can't cook? She say that old bag a bones ain't eating cause I can't feed her?» (K. Stockett «The Help»).

2) inability to express thoughts in a logical way is manifested in the conversation cited below, in which incomprehension is a consequence of a vague, controversial and partly illogical formulation:

«So your conclusion was that he drowned?»

«Yes.»

«Was that unequivocal? Was there any doubt?»

«Yes, of course there's doubt. There's always doubt. You're not-» $<\ldots>$ «Do you wish to say that your report is inaccurate?» $<\ldots\rangle$

«The report is accurate,» said Horace Whaley. «I-» (D. Guterson «Snow Falling on Cedars»).

\section{Conclusion}

The success of interpersonal communication that takes place in the process of joint activity depends on the correctness of the perception of the message coded by the speaker, their communicative intention. The message decoded in the wrong way leads to a communicative failure, that is complete or partial incomprehension of the utterance by the speaker, as a result of which the speaker's communicative intention is not realized.

The actual research singles out nineteen possible causes of communicative failures that can be classified into six groups: disregard for the norms of social and speech etiquette, inadequate perception of the interlocutor and phenomena of the extralinguistic reality, communicative failures as a result of the influence of the personality of the participants of communication and background information that the interlocutors possess, failure in the realization of the communicative intention of the speaker, intentional or unintentional striving for a communicative failure, inability to r build a speech utterance.

On the whole, communicative failures are not determined by the use of certain epistemic modal markers of possibility or necessity. However, introduction of markers of epistemic possibility in particular situations could have mitigated the effect of the utterance on the addressee, thus avoiding a communicative failure. The further field of investigation may be the study of the causes of communicative failures in various communicative situations.

\section{References}

[1] Bykov AYu (2006), What is communication. Izvestiya Uralskogo Universiteta, 40, pp: 86-97.

[2] Gorelov IN (1990), Communication. Linguistic Encyclopedic Dictionary. Moscow, Soviet Encyclopedy.

[3] Gass SM, Varonis EM (1991), Miscommunication in Nonnative Speaker Discourse. Miscommunication and Problematic Talk. Newbury Park, CA: Sage, pp: 121-145.

[4] Olsina EC (2002), Managing understanding in intercultural talk: An empirical approach to miscommunication. Atlantis, XXIV (2), pp: $37-57$.

[5] Akhmanova OS (2007), The dictionary of linguistic terms. Moscow: KomKniga.

[6] Fishman JA (1972), The sociology of language: an interdisciplinary social science approach to language in society. Rowley, MA, Newbury House, xiii + 250.

[7] Matveyeva TV (2003), Learner's Dictionary. Moscow, Flinta, Nauka.

[8] Formanovskaya NI (2002), Speech communication: communicative and pragmatic approach. Moscow, Russian language.

[9] Mustajoki A (2006), Theory of Functional Syntax: from Semantic Structures to Linguistic Expressions. Moscow, Languages of Slavic Culture.

[10] Shakirova RD, Sadrieva GA, Safina AR, Almikaeva IG, Galimullina AF (2016), Evidentiality, Epistemic Modality, and Epistemic Status. International Journal of Applied Linguistics \& English Literature. Australia, Australian International Academic Centre, 5(5), pp: 32-38.

[11] Bazzanella C, Damiano R (1999), The interactional handling of misunderstanding in everyday conversations. Journal of Pragmatics, 31, pp: 817-836.

[12] Verdonik D (2010), Between understanding and misunderstanding. Journal of Pragmatics, 42(5), pp: 1364-1379.

[13] Bugrova SYe (2012), Phenomenon of a communicative failure in the scope of communicative-pragmatic paradigm. Bulletin of Chelyabinsk State University. Philology. Art studies, 68(21), (275), pp: 22-26.

[14] Kiseleva SV (2012), The analysis of communication failure and their actualizer in political discourse. Bulletin of Pushkin Leningrad State University, Philology series, 7(2), pp: 146-153.

[15] Popova YeA (2014), Reasons of communicative failures in English dialogic speech. Bulletin of Moscow State Linguistic University. Humanities series, 25 (711), pp: 75-88.

[16] Shelestyuk YeV (2010), Experience of pragmalinguistic analysis of communicative failures in the communicative act-dialogue in the Internet. Materials of III international scientific conference "Topical problems of modern scientific knowledge", Part I. Pyatigorsk, PGLUizdat, pp: 359-366.

[17] Airenti G, Bara BG, Colombetti M (1993), Conversation and behavior games in the pragmatics of dialogue. Cognitive Science, 17, pp: 197-256.

[18] Airenti G, Bara BG, Colombetti M (1993), Failures, exploitations and deceits in communication. Journal of Pragmatics, 20, pp: 303 326.

[19] Bara BG (2005), Cognitive Pragmatics. MIT Press, Cambridge, MA.

[20] Bosco FM, Bucciarelli M, Bara BG (2006), Recognition and repair of communicative failures: A developmental perspective. Journal of Pragmatics, 38, pp: 1398-1429.

[21] Kneva NK (1999), Integral approach to the problem of communicative failures: PhD Philological sciences. Tver.

[22] Yermakova ON, Zemskaya EA (1993), On building typology of communication failures (on the material of natural Russian conversation). The Russian Language in its Functioning. Communicative and pragmatic aspect. Moscow, pp: 30-63.

[23] Gorodetsky BYu, Kobozeva IM, Saburova IG (1985), On typology of communicative failures. Dialogic interaction and presentation of knowledge. Novosibirsk, VTsSo RAN, pp: 64-78.

[24] Mustajoki A (2015), Communication failures through the prism of the speaker's needs. Language and thought: Contemporary cognitive Linguistics. Moscow, Languages of Slavic Culture, pp: 543-559.

[25] Vinogradov SI, Graudina LK, Danilenko VP et al. (2006), Culture of Russian Speech. Moscow, NORMA. 